\title{
Wider Economic Impacts in Transport Infrastructure Cost-Benefit Analysis - A Bridge Too Far?
}

\section{Leo Dobes and Joanne Leung ${ }^{1}$}

\section{Abstract}

Proponents of transport infrastructure have in recent decades sought to augment the estimated benefit of major projects beyond conventional cost-benefit analysis. Improved transport links are claimed to increase Marshallian external economies of scale; to reduce transport costs experienced by imperfectly competitive industries, and so induce them to increase their output; and to increase supply of labour, in response to lower transport costs, and thereby increase GDP and tax receipts. Estimates of the value of these three additional effects have resulted in multipliers and 'uprate factors' that appear to be applied by some government agencies to transport sector benefits calculated using conventional CBA. However, empirical estimates of these effects are likely to be exaggerated.

\section{Introduction}

A conventional cost-benefit analysis (CBA) of transport projects invariably focuses on items such as savings in travel time and fuel costs, as well as on changes in any externalities such as negative environmental outcomes or vehicle

\footnotetext{
1 The Australian National University and the New Zealand Ministry of Transport, respectively. Correspondence to Leo.Dobes@anu.edu.au. The authors wish to thank the editor and an anonymous referee for some very useful comments. They are also grateful to the Australia and New Zealand School of Government for providing research funding.
} 
crashes. Aggregated, they provide a measure of the change in the 'generalised cost' of travel attributable to the provision of new or enhanced transport infrastructure such as a road, a railway or a bridge. The underlying assumption is that all markets, including transport-using ones, are perfectly competitive.

Conventional CBA nevertheless requires examination of secondary, transportusing markets that are distorted due to factors such as taxes or imperfect competition (see, for example, Boardman et al. 2011: ch. 5). On the basis that market economies are in fact subject to various distortions, policymakers in the United Kingdom in the 1990s began to explore the implications for the evaluation of transport projects. ${ }^{2}$

In recent years, the so-called wider economic impacts (WEI) ${ }^{3}$ of transport have been addressed in three separate categories: agglomeration effects, imperfect markets, and tax revenues from increased economic growth. ${ }^{4}$ Agglomeration effects were discussed by Alfred Marshall in the context of external economies that firms and workers can reap in larger markets. Firms benefit from interactions with 'correlated branches of industry', workers more easily find jobs suited to their particular skills, and employers better match available skills to jobs (Marshall 1948: book IV, chs X, XIII). The new economic geography and WEI literature have built on these concepts.

A second category of benefits is attributed to users of transport services working in industries that exhibit imperfect competition. Lower transport costs are assumed to translate into increased production and lower prices, thus benefitting society. Lower transport costs can be expected to increase production in both imperfectly competitive sectors and in more competitive industries. Part of this additional production (GDP) will flow to the government in the form of taxes and will be spent on other projects or programs of benefit to the community. Conventional transport CBA does not include this effect because it considers only the primary, transport market, so a WEI perspective adds it as an additional benefit.

\footnotetext{
2 The seminal work was carried out by SACTRA (1999), with a series of subsequent publications under the auspices of the UK Department for Transport (DfT). A selection of publications in the UK and elsewhere includes DfT (2005); Venables (2007); Vickerman (2007a, 2007b); Elhorst and Oosterhaven (2008); Mare and Graham (2009); Laird and Mackie (2010); Worsley (2011); Abelson (2011); Hensher et al. (2012); SGS Economics and Planning (2012a, 2012b); DfT (2014); and Byett et al. (2015).

3 Initially referred to as 'wider economic benefits' (for example, DfT 2005), some of the literature has since adopted the more appropriate term 'wider economic impacts', in recognition of the fact that many of the posited impacts relate to changes in GDP and employment levels, rather than to the social welfare measures used in CBA.

4 A fourth category - increased competition as a result of improved transport links between different markets - was posited in DfT (2005), but abandoned in DfT (2014: 1, fn 3) because it was not considered to be relevant in countries such as the UK, where transport links were already well developed, so that existing transport networks were 'unlikely to be a significant constraint on competition'. DfT (2010) applies WEI concepts to the appraisal of isolated housing developments, but this category is not examined separately below.
} 
Adjustment of standard CBAs using WEI concepts can increase the estimated benefits of a project substantially. In the case of the proposed light-rail link in Canberra, Capital Metro (2014: table 29) includes WEI effects that constitute 20 per cent of total benefits. There is some risk that multipliers or so-called uprate factors will be applied routinely to estimated benefits of transport projects.

Given the increased focus by Australian governments in recent times on transport infrastructure projects, it is important to ensure that the estimated WEI benefits are not exaggerated. In a budget-constrained world, any bias in the estimation of transport sector benefits would be at the expense of potentially meritorious projects in other sectors such as health or education. Aspects of WEIs are therefore examined below from both a theoretical and an empirical perspective.

\section{Wider economic impacts of transport infrastructure: Some theoretical considerations}

The standard analysis of the benefits of a transport-related project can be represented diagrammatically, as in Figure $1 .^{5}$ The vertical axis shows the generalised cost of transport: typically the cost paid for a trip, including travel time, fuel and any change in externalities such as vehicle crashes. The horizontal axis typically shows the number of trips. The demand curve therefore indicates the maximum willingness to pay for particular numbers of trips made. Figure 1 does not show the capital cost of the project, which is estimated separately.

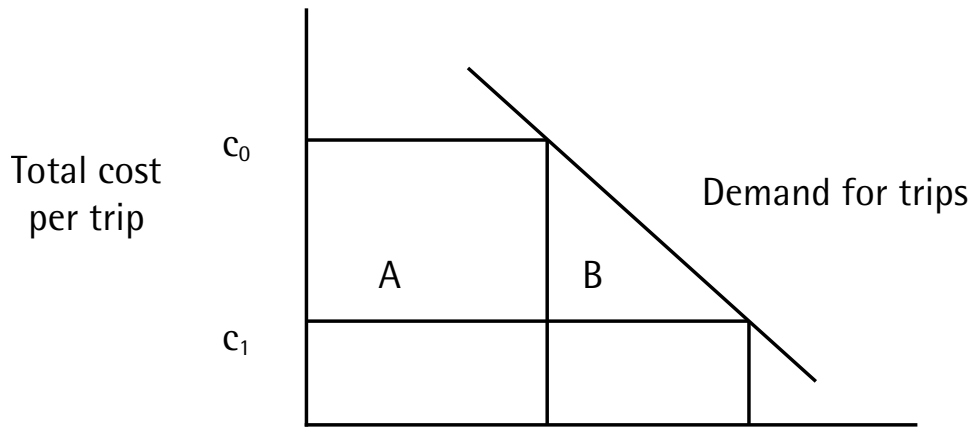

Number of trips

Figure 1: Change in consumer surplus for a transport-related project

5 A more realistic diagram could include an upward-sloping supply curve. As generated trips require estimation of consumer surplus on the basis of perceived cost, the diagram in ATC (2006: vol 5, p. 55) would be a more appropriate representation in the presence of a tax levied on fuel. 
Area A in Figure 1 represents the gain in consumer surplus to existing users; those already making trips but who experience lower costs because of improved infrastructure. Area B represents the gain in consumer surplus for additional trips or for new (induced or generated) travel.

A change in generalised cost as a result of a transport project yields a change in social surplus, and hence its benefit to the community. In a perfectly competitive economy, an increase in social surplus due to a reduction in the generalised cost of transport from $\mathrm{c}_{0}$ to $\mathrm{c}_{1}$ is mirrored in consumer surplus changes due to lower prices of goods and services in other sectors of the economy. As transport-using producers experience lower costs, their surpluses, and those of other factors of production (for example, workers' wages), also increase. Because the change in transport social surplus fully reflects changes in a competitive economy, it is not necessary to estimate welfare effects in individual secondary factor or product markets (Luskin and Dobes 1999: chs 2, 3).

In practice, secondary markets are not perfectly competitive. They may be distorted by any combination of external economies of scale, imperfect competition among firms, and taxation imposed by governments. A more sophisticated estimate of the benefits of a transport-related project needs to take into account the effects of such distortions.

\section{Agglomeration economies}

Alfred Marshall examined various aspects and examples of so-called technological external economies in his Principles of Economics. Regions and cities with a larger number of firms and range of industries were considered by him to benefit from specialisation: firms can more easily find workers with relevant skills, and workers can more easily find work that matches their skills. Steam transport, the printing press (for printing trade journals) and the telegraph were responsible for removing obstacles to specialisation and hence for engendering external economies of scale reaped by individual firms in an industry through enhanced communication (Marshall 1948: ch. X, book IV, 321).

An increase in the aggregate scale of production in an industry will increase the extent of external economies, allowing individual firms within that industry to produce at lower cost. Provided that an adequate supply of materials is available, and provided that increased density will not result in 'want of fresh air and light', Marshall considered that an increase in population would be 'likely to lead to a more than proportionate increase' in social welfare (Marshall 1948: book IV, ch. XIII). 
Many of Marshall's ideas have been taken up in the modern literature ${ }^{6}$ on agglomeration (economic mass) and spatial economics. The term 'economies of agglomeration' refers to the additional benefits that firms and individuals gain by moving to areas where the density of economic activity is higher. As Marshall indicated, however, the positive economies of agglomeration may be reduced or offset by negative externalities such as congestion and environmental degradation.

Firms operating in denser markets gain from lower-cost access to both their customers and their suppliers. They also gain from the positive spillover of better access to information about conditions in their industry; knowledge is gained about innovations generally if they are 'clustered' physically close to each other, especially because of face-to-face interaction between employees, and their movement between jobs. ${ }^{7}$ There may also be opportunities to reduce costs by sharing costly manufacturing equipment and infrastructure within an industry. Firms are also able to draw on a wider pool of labour and to increase their access to specialised skills.

Workers benefit from a larger agglomeration of firms because they can more easily find other jobs if their firm ceases production. By finding jobs that better match their skills, workers can also increase their wages, reflecting their higher productivity in a more appropriate position. Employment in a larger city may also offer greater recreational opportunities.

It is not necessary for a worker to actually move to a large town or city. Construction of transport infrastructure that reduces the generalised cost of travel (travel time, fuel, externalities) will effectively bring workers closer to firms and to each other. The 'effective density' of the area where production occurs will increase because workers can more easily reach it, even if they do not relocate their residence.

If more workers are willing to commute because transport costs have been reduced, firms gain access to a larger pool of workers and their particular skills. It is recognised, however, that reduced generalised costs of transport may also result in some countervailing reduction of effective density if workers or firms relocate further away from the central business district.

\footnotetext{
6 Krugman (1991a, 1991b) is generally credited with revitalising the study of economic geography by incorporating spatial factors and increasing returns into economic analysis.

7 Jaffe et al. (1993) show that new patent applications are 5 to 10 times more likely to cite patents from the same metropolitan area compared to patents from outside it, a reflection of greater exchange of information by firms and workers located in proximity to each other. However, extensive debate took place in the first half of the twentieth century on the exact nature of economies of scale, with their existence initially being portrayed as 'empty boxes' by Clapham (1922) and others.
} 


\section{Increased output in imperfectly competitive product markets}

Conventional transport CBAs implicitly assume a situation of perfect competition throughout the economy, including in sectors that use transport services to obtain inputs and deliver outputs. In a perfectly competitive situation, users of transport services for commuting and for freight will pay a price that matches the value to them of the services. Because transport services are a derived demand, conventionally estimated consumer surplus provides a satisfactory measure of social surplus gained throughout the economy.

The situation is different in the case of business users operating in imperfectly competitive markets. Where businesses have market power, a reduction in transport costs is likely to have two separate effects. One effect, already captured in conventional CBA, is an increase in consumer surplus accruing to business users of transport services from additional (generated or induced) trips: triangle B in Figure 1.

The other, additional effect represents an increase in social welfare, if lower costs induce transport-using imperfectly competitive industries to increase their output, because the quantity of goods and services available to society is increased. This is most easily illustrated in the extreme case of a monopoly in Figure 2.

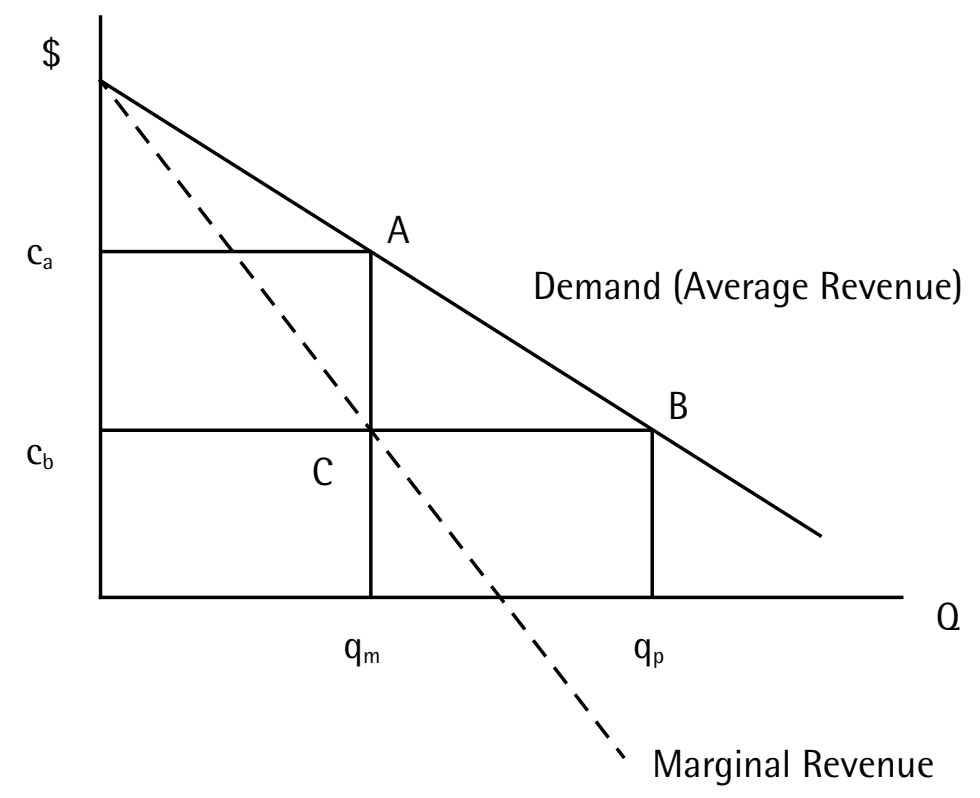

Figure 2: Welfare gain from increased output by monopolist 
In Figure 2, the monopolist has a constant short-run marginal cost supply curve at $\mathrm{c}_{\mathrm{b}}$. Equating marginal cost with marginal revenue, the monopolist produces $\mathrm{q}_{\mathrm{m}}$ while charging a price of $\mathrm{c}_{\mathrm{a}}$, which customers are willing to pay, given their demand curve. The monopoly profit made by the firm is equal to the rectangle $\mathrm{c}_{\mathrm{a}} \mathrm{c}_{\mathrm{b}} \mathrm{CA}$. The monopoly profit is not in itself an economically inefficient result because both the monopolist and customers are members of society. What one part of society loses, the other gains, so there is no net welfare loss; merely a redistribution of income. Society does, however, lose the consumer surplus triangle $\mathrm{ABC}$ because the monopolist has restricted profit-maximising production to $\mathrm{q}_{\mathrm{m}}$, whereas a perfectly competitive market would have produced an output of $\mathrm{q}_{\mathrm{p}}$. Social welfare can thus be enhanced by increasing output in the direction of the competitive market level of $\mathrm{q}_{\mathrm{p}}$.

Figure 2 can be extended to illustrate the less extreme examples of imperfect competition for duopoly and oligopoly (see, for example, McCloskey 1985: ch. 21). As long as they produce identical products and are otherwise indistinguishable, two Cournot duopolists would end up producing equal shares of output and charge the same prices. A Cournot solution for three or more oligopolists would similarly produce equal shares of output at equal prices. A Bertrand solution would provide a similar outcome, but a Stackelberg equilibrium will result in unequal shares of overall output.

The Cournot, Bertrand and Stackelberg approaches result in higher-thanmonopoly outputs, with prices below the monopoly price. As the number of oligopolists increases, increasing proportions of the triangle $\mathrm{ABC}$ that was a deadweight loss under monopoly conditions are reclaimed by society. The outcome in the case of a large number of firms approaches point $B$ in Figure 2, the perfectly competitive outcome where society reclaims the whole of the triangle.

The WEI literature assumes Cournot competition and calculates an 'uprate' factor by which benefits accruing to business travellers in a standard CBA are multiplied. The 'uprate factor' is based on the Ramsey (1927) uniform pricing model which provides a social welfare maximising rule for a monopoly price level. ${ }^{8}$ It is a combination of the percentage markup of the monopoly price above marginal cost $\left.\left(\left(c_{a}-c_{b}\right) / c_{b}\right)\right)$ and the price elasticity of demand. Kernahan and Rognlien (2011: 116-21) provide a detailed mathematical exposition.

8 Originally developed by Ramsey (1927) for efficient taxation, the method is also applicable to natural monopolies (Sharkey 1982) and utility pricing. Brown and Sibley (1986: 198-9) summarise use of the model to identify efficient prices in the presence of network externalities in telecommunications services. 


\section{Changes in the labour market}

DfT (2005: paras 109, 118) summarises the effect of improved labour supply as follows:

If a transport improvement facilitates increased GDP, there will be tax consequences, whether the additional work involves more people in employment, additional hours, or moving to more productive jobs. The welfare effects of small changes in time savings will be marginal for individuals, but the GDP effects can be more substantial for the minority of people affected ... in some cases, relatively small welfare benefits from time or cost savings can lead to significant GDP effects. There is no theoretical reason to be certain whether the welfare effect of such savings will be smaller or larger than the GDP effect ... [It is] likely to be significant only where a transport scheme relieves a significant transport constraint, and then only for a minority of individuals (insofar as transport cost changes lead to a change in employment or in employment patterns).

That is, a reduction in the cost of travel due to a transport improvement may have a positive effect on the supply of labour in the following three ways (DfT 2005: section 3.4):

- More people may choose to work because commuting time, and hence the generalised cost of travel, is reduced.

- Some may elect to work longer hours because less time is spent on commuting.

- Relocation of firms and workers to higher-productivity (and hence higherwage) areas because better transport makes the area more attractive and accessible to firms and workers.

The additional output made possible by an increased supply of labour is reflected in an increase in GDP or its sub-national equivalent.

The benefit to the additional people who now travel to work due to lower transport costs is captured in conventional cost-benefit analysis in the 'generated demand' triangle (B in Figure 1). Worker-travellers take their decision to increase travel (or not) on the basis of after-tax earnings. However, the wage paid to the worker by the employer includes payroll and income taxes, because it is the total before-tax wage that reflects the worker's contribution to the value of the additional output gained by the employer.

The tax component forms part of the additional value of production attributable to the willingness of workers to undertake additional employment and to the higher wages earned by some in more productive jobs. Additional tax revenues can be used to fund other socially desirable projects that would otherwise not 
have been funded, or they can be used to reduce taxes imposed elsewhere in the economy. They therefore constitute a social benefit, an additional impact that should be captured in a transport-related CBA.

\section{Wider economic impacts of transport infrastructure: Some empirical doubts}

Estimation of posited WEIs is largely an empirical issue. Because time-constrained jurisdictions will be tempted to apply plug-in 'uplift' or 'uprate' factors on an almost automatic basis, the empirical aspects are important. In particular, routine or automatic application of WEI values for transport infrastructure risk exaggerating the estimated net benefits.

\section{Agglomeration economies}

Conceptually, agglomeration benefits are measured as the increase in output (GDP) due to the implementation of the transport project. A key variable that requires estimation is therefore the elasticity of total productivity with respect to the effective density of employment for industry i in area $j$.

However, the Achilles heel of empirically estimated agglomeration economies is the need to demonstrate causality. In particular, it is necessary to establish that changes in productivity or GDP are due to an increase in effective density generated by a specific transport project. This condition is rarely, if ever, provided in transport CBAs that include WEI benefits.

Paucity of relevant data and the analytical effort required to estimate agglomeration benefits can thus encourage unwarranted use of 'uplift' factors. Such factors may be derived from large cities like London, whether or not they are appropriate to local project circumstances. Mare and Graham (2009: 4) add that confounding effects in correlations may also bias estimated productivity impacts upwards.

Another concern is that changes in productivity may be attributed solely to transport projects, potentially risking a form of confirmation bias. While supporting infrastructure - such as the availability of high-speed internet - may not be as conspicuous as a major highway or rail upgrade, it may play an important role in increasing urban productivity. Some (for example, Florida 2003) might similarly argue that entertainment, high-level educational facilities and lifestyle ambience are also essential to attracting the 'creative class' of high 
productivity individuals to jobs in cities. The contribution of this 'reactive class' to productivity may also be wrongly attributed to transport infrastructure due to the difficulty of isolating different effects.

On a broader level, use of GDP or its sub-national equivalents is not compatible with the measures of welfare used in CBA. GDP is compiled on the basis of market transactions that do not include externalities or non-marketed benefits such as the value of travel time or the value of statistical life. Further, Laird and Mackie (2010: 1-2, para 5.1.3) warn in a report on British studies that estimates of the growth in gross value added (GVA) appear to be exaggerated because they:

... are significantly in excess of the Present Value of Benefits used in conventional cost benefit appraisal ... Clearly these GVA estimates are large and, on the basis that they also exceed welfare benefit estimates, give rise to questions of consistency with the methods used to appraise transport projects ... the methods available to estimate the potential GVA impact of a region post a transport investment are still in their infancy and need work to ensure they pass internal consistency and robustness tests.

Even the fundamental issue of 'standing' - an elemental concept in any CBA - appears to have been largely neglected in the literature on WEIs. Reporting studies of transport projects in Germany and China (para 2.2.4) that do not address the issue explicitly, Laird and Mackie (2010: para 2.1.5) comment that:

An improvement in transport supply in one region will make that region more accessible to other regions and potentially result in the displacement of economic activity to the 'other' regions. This is known as the two-way road effect. Thus an improvement in transport supply in one region may increase the size of the economy at the national level but reduce it at a sub-national level.

In sum, empirical analysis of agglomeration economies can be problematic, if not misleading, due to deficiencies in available transport models, the paucity of relevant data for specific projects, absence of demonstrated causality, and neglect of established principles of CBA. Detailed critiques are provided by DfT (2014); Worsley (2011); Laird and Mackie (2010); Graham et al. (2009); and Byett et al. (2015), among others.

\section{Output change in imperfectly competitive product markets}

Drawing on a number of price-cost studies for UK manufacturing industries and economy-wide elasticities, DfT (2005) recommended an uprate factor of 0.1 , based on a price-cost margin of about 0.2 and a price elasticity of demand of 0.5. That is, for imperfectly competitive firms, any welfare gain due to business 
travel time savings, as well as transport reliability gains, should be increased by 10 per cent above values estimated using the conventional analysis in CBA. DfT (2014) confirmed this recommendation.

However, adjusting benefits estimated in standard transport CBA for the welfare effects of increased production in imperfectly competitive industry is questionable on both theoretical and empirical grounds.

For all its elegance, the Cournot description of oligopolistic behaviour is flawed. Its assumption of the production and sale of perfectly homogenous goods by all the oligopolists is unrealistic. An equally unrealistic assumption is that competitor oligopolists will not change their behaviour in response to an initial move by one of them. This is particularly so for a small number of oligopolists where the actions of one will have a non-trivial effect on the market available to the others. The countervailing assumption of a large number of oligopolists raises the lack of realism in assuming homogeneity of all goods and services sold.

A second limitation of the WEI approach is that there is no general economic theory of oligopoly. The perspectives offered by Bertrand and Stackelberg are variants on the Cournot theme, but Hotelling's (1929) analysis of spatial oligopoly where competitors form clusters, illicit cartel arrangements such as tacit collusion, and game theoretical approaches offers alternative descriptions of oligopoly behaviour. ${ }^{9}$ A popular alternative representation of oligopolistic behaviour is the kinked demand curve ${ }^{10}$ shown in Figure 3.

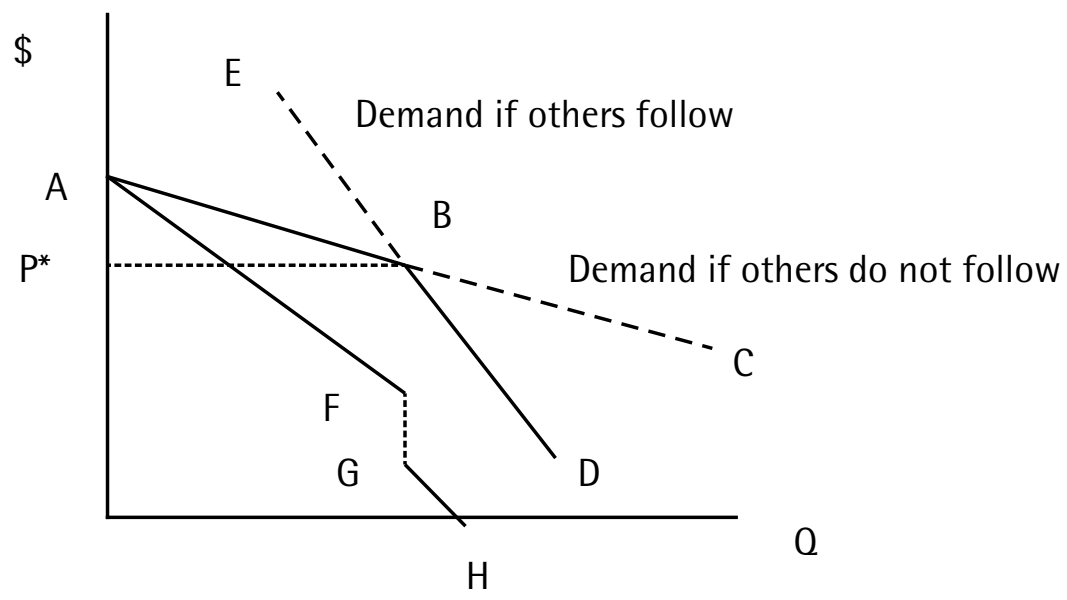

Figure 3: The kinked demand curve interpretation of oligopoly

\footnotetext{
9 Monopolistic competition is another form of imperfect competition (see, for example, Chamberlin 1932) but generally offers indeterminate solutions. It does not appear to feature in the WEI literature.

10 Variously attributed to Sweezy (1939) and Hall and Hitch (1939) who apparently published essentially the same model independently, but at much the same time.
} 
There are two demand curves in Figure 3. Demand curve ABC assumes that competitor oligopolists will not follow if one of them changes the price charged for a good or service. Demand curve EBD makes the opposite assumption, that competitors will set similar prices to changes made by one of their number. The composite demand curve is $\mathrm{ABD}$, and the corresponding marginal revenue curve AFGH is discontinuous between $\mathrm{F}$ and $\mathrm{G}$ to reflect the kink at $\mathrm{B}$.

Assume that an initial equilibrium price for heterogeneous products has been established around $\mathrm{P}^{*}$, perhaps due to some form of weak collusion. One of the oligopolists may try to reduce their price to increase sales, acting in the belief that others will not follow (the BC segment of demand curve ABC). In fact, it is likely that others will try to match the lower price, so the first-mover oligopolist will end up increasing sales only along the BD segment of demand curve EBD. In contrast, a price increase by the first mover in the belief that other oligopolists will follow along segment EB is likely to be resisted; the first mover will simply lose sales as it follows segment $\mathrm{AB}$. It is therefore likely that the market price will hover ${ }^{11}$ around $\mathrm{P}^{*}$.

The kinked demand curve scenario therefore posits sticky prices and quantities in oligopoly industries. Were this approach to be preferred to the Cournot solution, then reductions in transport costs for business travellers from imperfectly competitive industries could not result in increased social surplus. Determining which approach is the more realistic representation of imperfect competition in any particular industry would require detailed analytical effort.

However, the WEI literature typically adopts a Cournot approach without justification, raising the suspicion that it offers a convenient means of calculating additional benefits using a plausible theoretical basis. One can only conclude that the automatic application of 'uprate factors' based on the (typically unjustified) Cournot perspective results in overestimation bias when calculating the benefits of transport projects.

Even identifying imperfectly competitive firms may be empirically difficult. Increasingly sophisticated use of the internet by producers and distributors (The Economist, 2 May 2015) is likely to increase the degree of competition in a range of other industries. Companies like Uber and Lyft, for example, are pressuring governments to allow individuals to offer passenger transport services in competition with taxis. And according to Tyers (2014: 6), 'the precise extent of imperfect competition in Australia's service industries is difficult to quantify'.

11 Expositions of the kinked demand curve typically show changes in marginal cost (MC) as shifts in the MC curve within the FG discontinuity to assert indeterminacy of price formation even with changes in cost of production, and hence some rigidity in the overall quantity produced (point $\mathrm{H}$ in Figure 3). The main drawback of the approach is that it does not explain how the initial price $\mathrm{P}^{*}$ was determined. 
Finally, the WEI literature appears to have adopted a constrained, linear approach to the issue of imperfectly competitive industries. In Australia, at least, some such industries (chemists, newsagents, some postal services, etc) are imperfectly competitive due to legislated rigidities. Even if transport costs were to fall, there might be little reason for firms to decrease prices and increase sales. Moreover, institutional rigidities, such as after-hours penalty rates, and Occupational Health standards, such as truck driver hours, are likely to limit any price reductions.

\section{Changes in the labour market}

A transport intervention that reduces the generalised cost of transport to a commuter can be thought of as an increase in the effective wage. It is therefore possible to estimate an elasticity of labour supply with respect to effective wages, and to use it to estimate a change in the level of employment. The product of the change in employment and GDP per worker (average labour productivity) yields the overall change in GDP.

In theory, the addition of increased labour income tax receipts should be added to the benefits estimated in a conventional transport CBA. However, the approach proposed in the WEI literature is one-sided with regard to the effect of transport projects on taxation receipts and is therefore likely to result in overestimation of benefits.

It is - or should be - good practice in CBA to include the social cost of the deadweight loss resulting from the increased taxation or borrowing that is needed to fund a large project. Part of the reason for the deadweight loss is the reduced level of economic activity due to the depressive effect of the increased taxation. In other words, funding a large project, other than by reducing other government expenditures, will reduce GDP.

Infrastructure projects that can raise significant amounts of additional taxation receipts due to the postulated increase in labour supply and hence GDP, would arguably also be significant enough to require substantial financial resources. Raising the requisite finance would have some offsetting negative effect on GDP and hence taxation receipts.

However, this latter aspect of a negative effect on GDP due to financing of projects is ignored in the WEI literature. Failure to include both the positive and negative GDP/taxation effects of an infrastructure project can only result in a less-than-impartial analytical approach that will bias upward any estimate of the benefit. 
A further problem that may arise is inconsistency in the analysis itself. Unless the 'tax collected' effect is consistent with the 'standing' adopted for the underlying cost-benefit analysis, estimated benefit levels may be exaggerated. This is particularly true in cases where labour income tax is collected at the national level, but the analysis is carried out from a sub-national perspective such as that of a state or region.

A case in point is the Capital Metro (2014: table 28) analysis of a proposed lightrail link for Canberra. The standing adopted is not stated, but is implicitly that of Canberra. However, the estimated benefits of the project include Federal income tax, presumably because of an automatic application of the WEI approach. The present value of the estimated tax receipts is more than 15 per cent of the WEI amount included in the overall CBA result.

Obviously, labour income tax collected at the national level cannot constitute a benefit to residents of Canberra unless the Australian government hypothecates the tax receipts to the Australian Capital Territory. Thoughtless, automatic application of WEI effects can therefore also lead to exaggerated estimates.

\section{The treatment of wider economic impacts in Australia and New Zealand}

A report to the Council of Australian Governments Reform Council by the consultants SGS (2012a) reviewed the literature on agglomeration economies and provided estimates of projected changes to metropolitan GDP. It was based on case studies of proposed transport projects in Melbourne and Adelaide, and greenfield housing development in urban fringe areas of Sydney.

The SGS (2012a) report adopts an approach similar to overseas studies by estimating changes in state gross value added (GVA) based on the correlation between effective job density (EJD) and labour productivity by statistical local area (SLA). EJD is derived using travel time rather than the generalised cost of travel.

However, SGS (2012a) also proposes a different approach to estimating 'uplift' in GVA, based on elasticities of changes in human capital due to changes in EJD. This new approach is based on the hypothesis (p.2) that households are 'knowledge intensive enterprises' in their own right, and that transport projects will open more opportunities to learn and acquire skills. It is not entirely clear from the report whether the acquisition of additional human capital is hypothesised as being due to better access to educational centres or to on-thejob training, but the calculated elasticities are based on the incidence of formal tertiary qualifications in each SLA. 
With regard to productivity effects of agglomeration, the points made by SGS (2012a) appear to confirm the critique offered by DfT (2014); Worsley (2011); Laird and Mackie (2010); and Graham et al. (2009), among others. For example, 'rather than firms being more productive because they are in a central location, firms that are more productive can command central locations', so that the direction of causality runs in the opposite direction to the one usually hypothesised. A further problem is that researchers are not able to obtain access to detailed firm-level productivity data in Australia, whereas overseas studies have been able to do so. Indexes of EJD also do not distinguish between 'jobs' and their relevance to a particular sector in terms of their contribution to GVA; for example, a bank teller and an investment banker will be treated as equivalent occupations. SGS (2012a) also acknowledges that the use of cross-sectional data at a particular point in time to estimate elasticities may not be appropriate for projecting changes in future productivity due to a transport intervention or land use strategy.

Given all these uncertainties, it seems incongruous that SGS (2007: table 14) should attribute over $\$ 17$ million out of a total of $\$ 85$ million in present value benefits to urban consolidation benefits as a result of replacing a railway level crossing with an underpass in suburban Springvale in Melbourne. Capital Metro (2014: table 18) attributes a similarly high proportion of about 20 per cent in WEIs in its estimate of the total benefits for a 13-kilometre light-rail connection between one suburb already served by a rapid bus service, and one out of the four existing Canberra town centres. ${ }^{12}$

Studies have also been undertaken in New Zealand. Mare and Graham (2009) used more detailed data than those available to researchers in Australia to estimate agglomeration elasticities. Kernohan et al. (2011: table 8.2) analysed imperfect competition through the prism of a Cournot model using the pricecost differences of New Zealand firms. They recommend an 'uplift factor' of 10.7 per cent be applied to business user benefits.

Agglomeration impacts or externalities are included in the NZ Transport Agency's (2013: 5-406-5-411) Economic Evaluation Manual. It includes weighted average agglomeration elasticities for New Zealand by industry, as well as the procedure to apply the agglomeration elasticities to estimate productivity gains by location. The uplift factor for imperfect competition is specified as 10.7 per cent of business user benefits, and an increased labour supply is considered to be capable of adding up to ' $10 \%$ of wider economic benefits over conventional benefits'.

12 Other reports on WEIs commissioned by Australian jurisdictions include SGS (2012b), KPMG (2012), and Hensher et al. (2012). At the time of writing, a detailed study of elasticities of productivity with respect to employment density was being undertaken by SGS under the aegis of the Australian Government's Bureau of Infrastructure and Transport Economics on behalf of Austroads. 
Face-to-face discussions with transport agencies in Australia and New Zealand in late 2014 revealed a general acceptance of the need to include WEIs in evaluations of transport projects. Central agencies were typically more guarded, emphasising the need to avoid the application of elasticity and other values obtained from overseas studies or from other projects, although current methodologies are broadly supported. Most of those interviewed recognised the potential pitfalls of double-counting impacts, the need to demonstrate causality, and the limitations imposed by data availability.

Infrastructure Australia (2013: 11) notes that WEIs may not always be positive and that 'the availability of Australian specific data needed to calculate WEIs is currently sub-optimal'. It states that it will treat estimates of WEIs 'separately to the traditional CBA', but is nevertheless broadly supportive of their inclusion in proposals for infrastructure spending.

\section{Is routine application of WEI factors going too far?}

Vickerman (2007b: 4) provides a comprehensive review of the debate regarding the existence of wider economic benefits, distinguishing between macro-level and micro-level approaches, and noting the difficulty of 'knowing whether an elasticity obtained from the macro-study is in any way applicable to a single investment decision'. After reviewing differences in approach in the estimation of elasticities in macro-studies (output, productivity, or employment), the issue of direction of causality, and use of land-use transport interaction (LUTI) models versus computable general equilibrium (CGE) models, he points out that most of the empirical evidence he has reviewed relates to ex-ante studies. He cites 'one of the relatively few ex post studies' by Hay et al. (2004) to the effect that '... a very significant project, the Channel Tunnel, has not produced significant wider benefits over its first ten years of operation, at least on the regional economies close to the tunnel'.

Reviewing the effects of a number of TGV (Train a Grande Vitesse) projects between pairs of major French cities, Vickerman (2007b: 14) finds that traffic levels generally increased in both directions, but that there was no overall net impact on these major cities, although there was a tendency for increased concentration of economic activity towards them from their regional hinterlands. Vickerman (2007b: 16) concludes that 'what is clear is that there is little evidence of there being standard transferable [wider economic benefit] multipliers region to region or project to project' that can be applied to estimated benefits in individual ex-ante analyses. 
DfT (2014: section 5.2) reviews a number of data and modelling issues in the UK that can affect the robustness of estimates of WEIs. Lack of modelling of intra-zonal travel in transport models is considered likely to produce inaccurate estimates of agglomeration effects. Where transport models do not employ generalised cost matrices, there is likely to be bias in WEI assessments because changes in agglomeration effects depend on costs. Insufficient segmentation of modes in transport models may affect estimates of effective density; for example, if the model does not include a public transport mode. Finally, models may not cover the geographic area under consideration exactly, leading to unreliable results.

In a detailed review of using the UK GVA approach, rather than GDP, Byett et al. (2015: 94) noted that:

One issue that was not fully resolved was whether the benefits measured are additional or inclusive of the rule-of-half benefits measured within the standard transport appraisal ... Hence at this stage it is recommended that the GVA approach be used alongside the EEM [Economic Evaluation Manual, NZ Transport Agency], rather than as an additive effect.

More particularly from the perspective of this publication, in a summary table of pros and cons of the GVA methodology, Byett et al. (2015: 95, table 10.1) also conclude: 'The GVA approach is not consistently defined across different studies. Likewise density measures also differ across studies. These inconsistencies reduce the ability to compare model outcomes and calibrate model parameters.'

Abelson (2011) sums up his own review of the issues by concluding that 'searching for wider economic benefits is something of a holy grail in transport economics'.

\section{Conclusion}

Just as there is sometimes unjustified aversion to new ideas, it can also be the case that a new idea or approach is adopted without sufficient critical review. In the case of WEIs, enough caveats have become apparent to signal that a thorough review of the approach is desirable before its acceptance and automatic application to transport projects in Australia and New Zealand.

To ensure transparency, consistency and robustness in CBA studies of transport infrastructure projects, it would be highly desirable for all jurisdictions to undertake the following:

- A thorough review of the basic methodological principles used in the WEI approach, particularly from the perspective of its application to cost-benefit 
analysis. This should include ex-post assessments and their comparison with ex-ante evaluations.

- Peer-review by statisticians and econometricians of the reliability of available data in all jurisdictions, as well as the methodology used to estimate WEI parameters.

- Rigorous data collection and analysis to estimate the relative contributions of external economies of scale to productivity by transport, the internet, etc.

- Data collection to permit estimation of the number of business travellers from imperfectly competitive industries, as well as the output responses of those firms to improvements in transport services.

\section{References}

Abelson, P. 2011, 'The Wider Economic Impacts of Transport Infrastructure', Applied Economics, Sydney.

ATC (Australian Transport Council) 2006, National guidelines for transport system management in Australia, Commonwealth of Australia, Canberra.

Boardman, A.E., Greenberg, D.H., Vining, A.R. and Weimer D.L. 2011, CostBenefit Analysis. Concepts and Practice, 4th ed., Pearson Prentice Hall, USA.

Brown, S.J. and Sibley, D.S. 1986, The Theory of Public Utility Pricing, Cambridge University Press, Cambridge, UK.

Byett, A., Laird, J., Stroombergen, A. and Trodd, S. 2015, 'Assessing New Approaches to Estimating the Economic Impact of Transport Interventions Using the Gross Value Added Approach', Research Report 566, New Zealand Transport Agency, Wellington.

Capital Metro 2014, 'Full Business Case', Australian Capital Territory Government, Canberra.

Chamberlin, E.H. 1932, The theory of monopolistic competition, Harvard University Press, Cambridge, MA.

Clapham, J.H. 1922, 'Of empty economic boxes', Economic Journal vol. XXXII: 305-14.

DfT (Department for Transport) 2005, 'Transport, Wider Economic Benefits and Impacts on GDP', London.

-2010, 'Appraisal in the context of housing development', (in draft), Transport Analysis Guidance Unit 3.16, London. 
- 2014, 'Wider Impacts', Transport Analysis Guidance (TAG) Unit A2.1, London.

Elhorst, J.P. and Oosterhaven, J. 2008, 'Integral cost-benefit analysis of Maglev projects under market imperfections', Journal of Transport and Land Use 1(1): 65-87.

Florida, R. 2003, The rise of the creative class and how it's transforming work, leisure, community and everyday life, Pluto Press, North Melbourne.

Graham, D.J., Gibbons, S. and Martin, R. 2009, 'Transport Investment and the Distance Decay of Agglomeration Benefits', Imperial College, London. Available at: personal.lse.ac.uk/gibbons/Papers/Agglomeration \%20and \% 20 Distance\%20Decay\%20Jan\%202009.pdf.

Hall, R. and Hitch, C. 1939, 'Price Theory and Business Behaviour', Oxford Economic Papers 2: 12-45.

Hay, A., Meredith, K. and Vickerman, R. 2004, 'The Impact of the Channel Tunnel on Kent and the Relationships with Nord-Pas de Calais. Final Report to Eurotunnel and Kent County Council, Canterbury', University of Kent Centre for European Regional and Transport Economics, Kent, UK.

Hensher, D.A., Ellison, R. and Mulley, C. 2012, 'Assessing the Wider Economy and Social Impacts of High Speed Rail in Australia. Report Prepared for the Australasian Railway Association', Institute of Transport and Logistics Studies, University of Sydney, Sydney.

Hotelling, H. 1929, 'Stability in competition', Economic Journal 39(153): 411-57.

Infrastructure Australia 2013, 'Reform and Investment Framework Templates for Use by Proponents. Templates for Stage 7: Solution Evaluation (transport Infrastructure)', Infrastructure Australia, Sydney.

Jaffe, A.B., Trajtenberg, M. and Henderson, R. 1993, ‘Geographic Localization of Knowledge Spillovers as Evidenced by Patent Citations', Quarterly Journal of Economics 108(3): 577-98.

Kernohan, D. and Rognlien, L. 2011, 'Wider Economic Impacts of Transport Investments in New Zealand', Research Report 448, New Zealand Transport Agency, Wellington.

KPMG 2012, 'Long Run Economic and Land Use Impacts of Major Infrastructure Projects. Peer Review Report Prepared for Victorian Government Department of Transport'. 
Krugman, P. 1991a, Geography and Trade, Leuven University Press and The MIT Press, USA.

- 1991b, 'Increasing returns and economic geography', Journal of Political Economy 99(3): 483-99.

Laird, J. and Mackie, P. 2010, 'Review of Methodologies to Assess Transport's Impacts on the Size of the Economy', Institute for Transport Studies, University of Leeds, Leeds, UK.

Luskin, D. and Dobes, L. 1999, Facts and furphies in benefit-cost analysis: transport, Bureau of Transport Economics, Commonwealth of Australia, Canberra.

McCloskey, D.N. 1985, The applied theory of price, 2nd edition, Macmillan, New York.

Mare, D.C. and Graham, D.J. 2009, 'Agglomeration Elasticities in New Zealand', Motu Working Paper 09-06, Motu Economic and Public Policy Research, Wellington.

New Zealand Transport Agency 2013, Economic Evaluation Manual, Government of New Zealand, Wellington.

Ramsey, F.P. 1927, 'A contribution to the theory of taxation', Economic Journal 37: 47-61.

SACTRA (Standing Advisory Committee on Trunk Road Assessment) 1999, 'Transport and the economy: full report', Department for Transport, London.

SGS Economics \& Planning 2007, 'Springvale Level Crossing Grade Separation Project. Preliminary Cost Benefit Analysis', City of Greater Dandenong, Melbourne.

- 2012a, 'Productivity and Agglomeration Benefits in Australian Capital Cities. Final Report to the COAG Reform Council', SGS Economics and Planning Pty Ltd.

_ 2012b, 'Long Run Economic and Land Use Impacts of Major Infrastructure Projects', Report Prepared for the Victorian Government Department of Transport, Melbourne.

Sharkey, W.W. 1982, The theory of natural monopoly, Cambridge University Press, USA.

Sweezy, P. 1939, 'Demand Under Conditions of Oligopoly', Journal of Political Economy 47(2): 568-73. 
Tyers, R. 2014, 'Service Oligopolies and Australia's Economy-Wide Performance', Discussion Paper 14.18, Business School, University of Western Australia.

Venables, A.J. 2007, 'Evaluating Urban Transport Improvements', Journal of Transport Economics and Policy 41(2): 173-88.

Vickerman, R. 2007a, 'Cost-Benefit Analysis and Large-Scale Infrastructure Projects: State of the Art and Challenges', Environment and Planning B: Planning and Design 34: 598-610.

— 2007b, 'Recent Evolution of Research into the Wider Economic Benefits of Transport Infrastructure Investments', Discussion Paper 2007-9, Joint Transport Research Centre, University of Kent, UK.

Worsley, T. 2011, ‘The Evolution of London's Crossrail Scheme and the Development of the Department for Transport's Economic Appraisal Methods', Discussion Paper 2011-27, Institute for Transport Studies, University of Leeds, Leeds, UK. 
This text is taken from Agenda, Volume 22 - Number 1, 2015, edited by William Coleman, published 2015 by ANU Press, The Australian National University, Canberra, Australia. 